\title{
Geliat Ekonomi Pasar Ikan Palibelo Kabupaten Bima
}

\author{
Mochamad Noeryoko \\ STKIP Taman Siswa Bima \\ yokonoer78@gmail.com
}

\begin{abstract}
ABSTRAK
Dalam penelitian ini penulis membahas tentang geliat ekonomi pasar ikan palibelo fokus dari penelitian ini yaitu : (1) bagamana para pedagang mendapatkan stok barang dagangan. (2) bagaimana proses penjualan ikan di pasar Ikan Palibelo (3) bagaimana tingkat kesejahteraan pedangang di pasar ikan Palibelo. Penelitian ini menggunakan jenis penelitian kualitatif deskriptif, sumber data terdiri dari sumber data sekunder dan sumber data primer. Teknik pengumpulan data dilakukan melalui observasi, wawancara mendalam, juga dokumentasi. Hasil penelitian (a). pedagang ikan dipasar ikan Palibelo mendapatkan stok ikan dari pemilik tambak yang ada disekitar teluk Bima bagian tenggara berupa ikan bandeng yang biasa dipelihara ketika musim kemarau karena dimusim hujan tambak rentan terhadap banjir yang sering menyebabkan ikan terbawa banjir dan stok ikan laut lainnya diperoleh dari nelayan yan yang beroperasi di teluk Bima. (b). Pedagang dalam menjual dagangan membuka lapak dipasar ikan Palibelo yang ada di jalan nasional Bima Dompu tepatnya di depan bandara bagian selatan yang buka pada jam 08.00-17.30 Wita. (c). Kesejahteraan pedagang meningkat karena hasil penjualan ikan cukup banyak karena posisi pasar yang sangan strategis yang menghubungkan kota bima denga daerah kabupaten Bima bagian selatan dan kabupaten Dompu.
\end{abstract}

\section{Key Word: Geliat Ekonomi, Pasar Ikan Palibelo}

\section{PENDAHULUAN}

Teluk Bima memanjang dari utara keselatan pada ujung perairan ini cukup dangkal khusus dibagian tenggara banyak potensi alam yang bisa manjadikan masyarakat lebih sejahtera. Potensi yang bisa didapat yaitu dari pegunungannya disitu banyak tanaman yang bisa di produksi yaitu kacang tanah, kedelai, dan juga jagung yang hanya bisa berproduksi ketika musim hujan saja karena tipikal dari daerah perbukitan merupakan daerah tadah hujan jadi pertanian hanya berharap dari air hujan hal ini yang membuat produksinya hanya sekali dalam setahun, potensi peternakan juga bisa didapat dari derah sekitar teluk bima bagian tenggara karena terdapat padang rumput dan tanaman kecil lainnya yang cocok untuk menjadi pakan ternak yaitu kambing, sapi, kerbau dan juga kuda, keindahan teluk Bima ketika matahari terbenam juga bisa dimanfaatkan untuk tempat peristirahatan cocok untuk dikembangkan perhotelan yang menunjang perekonomian daerah dengan adanya pajak, dan wisatawan luar derah lebih tertarik untuk mengadakan perjalanan ke Bima karena fasilitas yang lengkap bagi orang luar ketika datang ke Bima. Pantai pantai teluk Bima tidak kalah cantik dibandingkan pantai di daerah lain terutama pantai kalaki yang cukup diminati masyarakat untuk melepas kepenatan dengan berekreasi dengan mandi dipantai dan juga makan-makan sehingga menimbulkan efek positif bagi masyarakat sekitar dengan menyediakan tempat tempat pesinggahan dan juga memjual berbagai macam makanan, menyewakan ban untuk menunjang aktifitas mandi di pantai. Potensi lainnya yaitu produksi garam yang cukup berlimpah pada musim kemarau. Untuk penelitian kali ini penulis membahas tentang potensi teluk Bima bagian tenggara yang berupa perikanan yang didapat dari tambak dan penangkapan diteluk Bima. 


\section{Ekonomi}

Menurut istilah kata ekonomi berasal dari bahasa yunani kuno yakni aikos yang artinya keluarga, rumah tangga serta nomos ialah peraturan, aturan, hukum. Secara etimologi atau secara bahasa, pengertian ekonomi ialah aturan rumah tangga ataupun manajemen rumah tangga, berupa aktivitas manusia yang berhubungandengan produksi, distribusi dan konsumsi. Sedangkan dalam Kamus Besar Bahasa Indonesia (KBBI) ekonomi memiliki beberapa pengertian yakni sebagai berikut: 1) Ilmu mengenai asas-asas produksi, distribusi serta pemakaian barang-barang juga kekayaan, seperti hal keuangan, perindustriandan perdagangan, 2) Pemanfaatan uang, tenaga, waktu dan sebagainya yang berharga; 3) Tata hidup perekonomian suatu negara; 4) Urusan keuangan rumah tangga, organisasi ataupun negara.

\section{Pasar}

Pasar tradisional adalah pasar yang pelaksanaannya bersifat tradisional tempat bertemunya penjual dan pembeli, terjadinya kesepatan harga dan terjadinya transaksi melalui tawar-menawar harga, ciri-ciri pasar tradisional : proses jual beli barang melalui proses tawar menawar, barang yang dijual umumnya keperluan rumah tangga, harga barang relatif terjangkau, dan area pasar biasanya di tempat terbuka. Syarat terbentuknya pasar yaitu: 1) Adanya penjual dan pembeli; 2) Adanya barang yang dijual belikan; 3) Terjadinya kesepakatan harga dan transaksi

\section{Ikan}

Ikan didefinisikan sebagai hewan bertulang belakang yang hidup di air dan dengan karakteristik memiliki insang yang berfungsi mengambil oksigen terlarut dalam air dan sirip digunakan untuk berenang. Ikan hampir ditemukan di semua tipe perairan di dunia dengan bentuk dan karater yang berbedabeda(Adrim, 2010)

Ciri-ciri umum dari golongan ikan adalah mempunyai rangka bertulang sejati dan bertulang rawan, mempunyai sirip tunggal atau berpassangan dan emempunyai operculum, tubuh ditutupi oleh sisik dan berlendir serta mempunyai bagian tubuh yang jelas antara kepala, badan dan ekor. Ukuran ikan bervariasi mulai dari yang kecil sampai yang besar, kebanyakan ikan berbentuk torpedo, pipih dan ada yang berbentuk tidak teratur (siagian, 2009).

Setiap ikan untuk dapat bertahan hidup dan berkembangbiak harus dapat beradaptasi terhadap lingkungannya. Kondisi lingkungan yang berpengaruh terhadap kehidupan ikan meliputi kondisi fisik dan kimia antara lain kadar garam, kedalaman, kecerahan, keadaan suhu, laju arus, dan dasar perairan (Trijoko Pranoto, 2006). Ikan memiliki pola adaptasi yang tinggi terhadap kondisi lingkungan, baik terhadap faktor fisik maupun faktor kimia lingkungan seperti $\mathrm{Ph}, \mathrm{DO}$, kecerahan, temperatur, dan lain sebagainya. Hal ini sangat penting bukan saja untuk mendapatkan makanan, tetapi juga untukmenyelamatkan diri dari hewan-hewan predator (Nibakken, 1988).

Mayr dalam Layli (2006) mengatakan bahwa ikan sebagai salah satu organisme yang menjadi kajian ekologi, sehingga harus dijaga kelestariannya. Sebagai langkah awal diperlukan kegiatan identifikasi terhadap organisme tersebut, idetifikasi adalah menempatkan atau emberikan identitas suatu individu melalui prosedur deduktif ke dalam suatu takson dengan menggunakan kunci determinasi.

Ikan dibedakan berdasarkan karakter-karakter umum yang dapat membedakan antara kelomok yang satu dengan kelompok yang lain. Adapunn karakter yang biasa digunakan dalam identifikasi ikan antara lain, yaitu: bentuk umum tubuh, bentuk dan jumlah sirip, bentuk mulut, bentuk ekor, dan perbandingan dan posisi anggota tubuh (Adrim, 2010). Klasifikasi ialah menetapkan definisi dari kelompok atau kategori menurut skala hierarki. Tiap-tiap kategori ini meliputi satu atau beberapa kelompok rendah yang terdekat, yang merupakan kategori rendah berikutnya (Saanin, 1968)

\section{METODE PENELITIAN}

Dalam penelitian ini peneliti menggunakan jenis penelitian menggunakan jenis penelitian deskriptif kualitatif, karena pada penelitian ini hanya menggambarkan gejala atau keadaan yang 
diteliti secara apa adanya dan data yang bersifat empiris (Sugiono, 2006). Lokasi dalam penelitian ini di Pasar Ikan Palibelo desa Belo kecamatan Balibelo kabupaten Bima.

Data primer atau data utama, yakni jenis data yang berkaitan langsung dengan obyek penelitian yang meliputi : diperoleh dari dari hasil penelitian dilapangan secara langsung, dan dari pihak-pihak yang bersangkutan dengan masalah yang akan dibahas dalam hal ini adalah penjual ikan, pembeli ikan, petani tambak bandeng, nelayan teluk bima. Untuk mendapatkan data primer mengggunakan 3 teknik yaitu (1)wawancara, wawancara adalah percakapan, tanya jawablisan antara dua orang atau lebih yang duduk berhadapan secara fisik dan diarahkan pada suatu masalah tertentu,(Usman Ahmad, 2008). Dalam pelaksanaan wawancara, penulis akan mengadakan wawancara dengan orang yangdianggap dapat memberikan informasi tentang geliat ekonomi pasar ikan palibelo. Pda dasarnya orang-orang yang diwawancarai berasal dari beberapa kalangan yang mengetahui fokus kajian dalam penelitian ini. wawancara dengan informan pada dasarnya untuk menciptakan hubungan antara pewawancara dengan informan dalam suasana yang biasa, bebas dan wajar tidak merasa terikat dengan suasana yang formal keadaan yang demikian menyebabkan informan merasa bebas dan tidak merasa terpaksa memberikan informasi yang diperlukan. Hasil wawancara tersebut dicatat langsung oleh penulis maupun direkam dengan megnggunakan alat perekam untuk selanjutnya diperbaiki pada saat penulisan laporan. (2) observasi, observasi adalah suatu aktifitas yaang sempit, yakni memperhatikan sesuatu dengan mata (Arikunto,2006). Teknik observasi inipenulis gunakan untuk mengamati secara langsung pada obyek yang diteliti untuk mengetahui suasana aktifitas pasar ikan Palibelo. Adapun langkah observasi yang dilakukan antara lain: 1) Melihat aktifitas jual beli ikan di pasar ikan palibelo; 2) Melihat alur barang dalam hal ini dari nelayan dan petani tambak menuju pasar ikan palibelo; 3) Melihat kondisi ekonomi penjual ikan di pasar ikan Palibelo
Metode selanjutnya adalah (3) Dokumentasi adalah suatu cara untuk memperoleh data dengan jalan mengumpulkan segala macam dokumen serta mengadakan pencatatan yang sistematis (Yousda, 1993). Sedangkan ahli lain mengatakan bahwah "metode dokumentasi adalah suatu cara untuk mencari data atau halhal yang berupa catatan transkrip" (Margono, 1997). Metode dokumentasi digunakan sebagai metode bantu untuk mengumpulkan data melalui peningggalan tertulis, seperti arsip-arsip dan termasuk juga buku-buku tentang pendapat, teori, dalil atau hukum-hukum yang berhubungan dengan masalah penelitian (Rachman, 1996).

Analisis data adalah proses mencari dan menyusun secara sistematis data yang diperoleh dari observasi, catatan lapangan, dan bahanbahan lain, selanjutnya data yang terkumpul dievaluasi menggunakan metode deduktif dan metode induktif. Teknik analisa data dalam penelitian ini dilakukan secara terus menerus sejak awal sampai akhir penelitian. Analisia data dalam penelitian ini menggunakan teknik deskritif yang ditekankan pada analisa kualitatif dengan teknik induktif dan deduktif, tidak menutup kemungkinan juga argumentasi (Arikunto. 2002)

\section{HASIL PENELITIAN}

\section{Pedagang Mendapatkan Stok Barang Dagangan}

Berdasarkan hasil penelitian pedagang mendapatkan stok barang dagangan sesuai observasi yaitu penjual mendapatkan ikan dari para nelayan yang beroperasi di sekitaran teluk bima nelayan itu berasal dari desa-desa sekitar teluk bima bagian selatan yaitu desa Darussalam, Sondosia, Sanolo, Panda dan Belo. Sumber lainnya yaitu ikan bandeng yang dibudidayakan oleh petani tambak dari desa Talabiu Kecamatan Woha dan desa Belo Kecamatan Palibelo. Bedasarkan hasil wawancara dengan Ina Sei sebagai penjual Ikan Bandeng "Nahu raka uta aka dou mantau ombo" (Saya dapat ikan dari orang yang punya tambak). Hasil wawancara dengan $\mathrm{H}$. Usman (Pemilik tambak) "Nahu mantau ombo mai hanta ba dou ma landa di kengge ncai" (saya yang punya tambak datang orang untuk 
mengambil ikan oleh orang yang jual ikan di pinggir jalan (pasar ikan Palibelo)

Sementara itu untuk ikan laut Umi Moa berkata "Nahu raka uta aka dou ma nggawi lao pukat" (Saya dapat ikan dari orang mancing dan pukat dilaut). Hasil wawancara denga Dae Bedo menyatakan" Uta raka nahu landa lalo borong aka dou amba uta kengge ncai"(ikan yang saya dapatkan dibeli secara borongan kepada orang yang jual ikan dipinggir jalan (pasar kan Palibelo).

\section{Proses Penjualan Ikan Di Pasar Palibelo}

Berdasarkan observasi dipasar ikan Palibelo para pedangang mengelar dagangan di pinggir jalan didepan bandara yang sudah modifikasi seperti lapak-lapak jualan, untuk meningkatkan penjualan para pedangan berinisiatif untuk menempatkan ikan-ikan itu dipring seng agar mudah dibawa berlarian untuk mengejar calon pembeli yang menghentikan kendaraannya untuk melihat ikan-ikan yang dijual oleh penjual ikan pasar ikan Palibelo. Menurut ibu Janibah beliau berkata "anae nami ke coco roci ku dou ma kemidi kendaraan di cai nae loaku raka dou weli"(anak, kita ini kejar dengan cepat orang yang berhentikan kendaraannya supaya cepat dapat pembeli), begitu juga menuturt ibu anisah "wati si coco roci na raka badou amba mekalai ni" ( kalau tidak kita kejar bisa-bisa kedahuluan oleh penjual yang lain)

\section{Tingkat Kesejahteraan Pedagang Di Pasar Ikan Palibelo}

Hasil wawancara dengan penjual ikan dipasar ikan palibelo ibu sarah beliau berkata " nami ke bantu rahi anae diruu kebutuhan senai-nai, alhamdulillah tamba-tambah kai belanja sembako" (kita ini bantu suami untuk kebutuhan seharihari, lhamdulillah untuk tambahan belanja sembako), selain itu ketika wawancara dengan ibu asiah beliau berkata" alhamdulillah anae nami loa weli-weli barang-barang kebutuhan sawaur raka kenaha amba uta akeke" (Alahamdulillah anak, kita bisa beli barang-barang kebutuhan setelah dapat untung dari jualan ikan ini)

\section{PEMBAHASAN}

Pedagang ikan pasar ikan Palibelo mendapat ikan dari para petambak bandeng yang berada disekitar teluk Bima bagian tenggara, petambak memelihara ikan bandeng tidak harus pergi untuk menjual hasil tambaknya tetapi para penjual ikan akan datang ketika sudah mendapat kabar dari petambak pada waktu panen tiba. Penjual ikan akan datang diagi buta ketambak untuk menungu ikan yang akan dikeluarkan dari tambak untuk selanjutnya akan di jual dipasar ikan Palibelo. Biasanya petani tambak ikan bndeng akan menjual ikan bandengnya secara berangsur dikarenakan kemampuan penjual ikan untuk menjual juga terbatas sehingga tidak bisa dikeluarkan semua akan tetapi berdasarkan permintaan dan harga pasaran ikan. Karena pasaran ikan bandeng berdasarkan kelangkaan atau melimpahnya stok ikan yang ada di tambak, ketika stok mulai menipis bisasanya diikuti dengan datang musim kemarau, ketika musim kemarau petanik tambak akan mengalih fungsikan tambaknya menjadi ladang garam sehingga stok ikan akan berkurang dan menyebabkan ikan bandeng akan naik

Penjual ikan setelah mendapatkan ikan dari petani tambak mereka menjual di pasar ikan Palibelo dengan menggelar ikan dipinggir jalan pasar ikan Palibelo terletak di tempat yang strategis yaitu jalan nasional yang menghubungkan Kota Bima Dengan Kabupaten Sumbawa sehingga jalan ini ramai dilewati oleh pengguna jalan sehingga memudahkan penjual ikan untuk menjajahkan dagangannya, karena jalan ini menghubungkan kota bima dengan wilayah kabupaten Dompu dan juga kabupaten Bima Wilayah selatan dan barat, sehingga simbosis mutualisme yaitu ketergantungan yang saling menguntungkan terjadi ketika pembeli memerlukan ikan ketika pulang dari bepergian tidak harus berhenti berlama-lama di pasar tradisonal hanya untuk berbelanja ikan karena penjual ikan akan menyuguhkan ikan dalam piring-piring seng yang siap dibawah lari kemana saja dimana ada orang yang berhanti untuk membeli ikan, jadi secara tidak langsung ibu-ibu penjual ikan itu melakukan jemput bola sehingga memudahkan calon pembeli untuk bertransaksi tanpa harus turun dari kendaraan.

Dengan adanya pasar ikan Palibelo ibu-ibu penjual ikan mendapatkan penghasilan samping 
untuk membantu para suami, yang biasanya sumber pendapatan dari pihak suami saja sekarang bisa dari dua sumber sehingga hal inilah yang membuat kesejahteraan keluarga para penjual ikan semakin meningkat. Hasil dari menjual ikan untuk memnuhi kebutuhan seharihari dilain pihak penghasilan suami untuk kebutuhan membangun rumah membeli barangbarang elektronik bahkan untuk memenuhi kebutuhan biaya sekolah anak-anak mereka. Dengan begitu secara tidak langsung akan meningkatkan pendapat keluarga dan akan meningkatkan taraf kesejahteraan masayarakat disekitar teluk bima bagian tenggara.

\section{PENUTUP}

Berdasarkan hasil penelitian tentang geliat ekonomi dipasar Ikan Palibelo maka dapat disimpulkan: 1) Petani tambak di teluk Bima bagian Tenggara menyediakan ikan bandeng untuk dijual dipasar ikan palibelo sehingga menguntungkan kedua bela pihak antara penydia ikan dan penjual ikan dipasar ikan palibelo; 2) Penjual ikan pasar ikan palibelo menjual ikan bandeng jualannya dengan cara jemput bola sehingga memudahkan pembeli ikan untuk mendapatkan ikan secara cepat dan praktis; 3) Kesejahteraan penjual ikan meningkat dengan adanya keuntungan yang didapatkan dari menjual ikan sehingga menambah pendapatan keluarga yang sebelumy hanya dari para suami untuk sekarang ini ada kontribusi dari pihak ibu-ibu.

\section{DAFTAR PUTAKA}

Adrim, M dan Fahmi, 2010, Panduan Penelitian Untuk Ikan Laut, Pusat Penelitian OseanografiLIPI, Jakarta.

Alwi, Hasan, 2007, Kamus Besar Bahasa Indoesia, Jakarta, Balai Pustaka

Arikunto, S, 2002, Metodologi Penelitian Suatu Pendekatan Proposal, Jakarta, PT. Rineka Cipta.

Layli, N, 2006, Identifikasi Jenis-Jenis Ikan Teleostei Yang Tertangkap Nelayan Diwilayah Perairan Pesisir Kota Semarang, Skripsi: Program Studi Biologi Fakultas Matematika Dan Ilmu
Pengetahuan Alam, Universitas Negeri Semarang, Semarang.

Margono, 1997, Metodologi Penelitian Pendidikan, Jakarta, Rineka Cipta.

Nybakken, J. W, 1988, Biologi Laut: Suatu Pendekatan Ekologis, (Alih bahasa oleh: H. M. Eidman, Koesobiono, D. G. Bengen, M. Hutomo, S. Sukardjo), PT Gramedia Pustaka Utama, Jakarta.

Rahman, 1996, Prosedur Penelitian, Jakarta, Rineka Cipta

Siagian, C, 2009, Keanekaragaman Dan Kelimpahan Ikan Serta Keterkaitan Dengan Kualitas Perairan Di Danau Toba Balige Sumatra Utara, Tesis: Program Studi Biologi Sekolah Pascasarjana Universitas Sumatra Utara, Medan.

Sugiono, 2006, Metode Penelitian Kuantitatif, Kualitatif Dan REDD, Bandung, Alfabeta

Trijoko dan S. Pranoto, 2006, Keanekaragaman Jenis Ikan Sepanjang Aliran Sungai Opak Daerah Istimewa Yogyakarta, Proseding Seminar Nasional Ikan IV: Fakultas Biologi Universitas Gajah Mada, Yogyakarta.

Yousda, Amiran, I Ine, Arifin, Zainal, 1993, Penelitian dan Statistik Pendidikan, Bumi Aksara, Bandung. 